\title{
Assembling $\mathrm{ZnO}$ Nanorods into Microflowers through a Facile Solution Strategy: Morphology Control and Cathodoluminescence Properties
}

\author{
Ying Lei, Fengyu Qu, Xiang Wu*
}

(Received 4 November 2011; accepted 27 February 2012; published online 26 March 2012.)

\begin{abstract}
In this work, flowerlike $\mathrm{ZnO}$ micro/nanostructures assembled from nanorods are obtained through a facile hydrothermal route. The experimental results indicated that the as-synthesized $\mathrm{ZnO}$ microflowers have an average diameter of $2 \mu \mathrm{m}$, composed of nanorods of an average diameter of $200 \mathrm{~nm}$ and a tapered morphology. $\mathrm{ZnO}$ with other morphologies were also obtained by varying the reaction conditions. Systematical conditiondependent experiments were conducted to reveal the growth mechansim of the microflowers. It is suggested that the zinc source types, solution $\mathrm{pH}$ value, and reaction temperature, as well as reaction time are responsible for the variations of $\mathrm{ZnO}$ morphology. Luminescence properties of $\mathrm{ZnO}$ microflowers were investigated through monitoring different parts of nanorods, showing good optical quality.
\end{abstract}

Keywords: Microflowers; Solution growth; ZnO; Cathodoluminescence

Citation: Ying Lei, Fengyu Qu and Xiang Wu, "Assembling ZnO Nanorods into Microflowers through a Facile Solution Strategy: Morphology Control and Cathodoluminescence Properties", Nano-Micro Lett. 4 (1), 45-51 (2012). http://dx.doi.org/10.3786/nml.v4i1.p45-51

The size and shape of low dimensional micro/nanoscale materials have a crucial influence on their physical and chemical properties, and on the properties of the integrated nanodevices due to the significant surface effect and quantum size effect [1-3]. In particular, hierarchical assembly of micro/nanoscale building blocks with tunable dimension and structure is essential for the fabrication of micro/nanodevices $[4,5]$. Inspired by this, hierarchical and complex micro/nanostructures have been the focus of intensive research in recent years. Fan et al. reported the assembly of $\mathrm{ZnO}$ nanorods on $\mathrm{SnO}_{2}$ nanowire backbones through a two-step growth process that combines the vapor transport and deposition process and a hydrothermal method [6]. Dick et al. synthesized heterogeneous GaP-GaAsP nanotrees via a stepwise deposition of gold nanoparticles on $\mathrm{GaP}$ nanowires [7]. $\mathrm{Ni}$ et al. reported flowerlike $\mathrm{ZnO}-$ $\mathrm{ZnS}$ heterogeneous microstructures built up by $\mathrm{ZnS}-$ particle-strewn on $\mathrm{ZnO}$ microrods by a hydrothermal route [8]. Some other flowerlike and hierarchical micro/ nanostructures (including metal or ternary compounds) were also reported, such as $\mathrm{Au}[9], \mathrm{Bi}_{2} \mathrm{SiO}_{5}[10], \mathrm{Bi}_{2} \mathrm{~S}_{3}$ [11], $\mathrm{ZnS}$ [12], $\mathrm{InP}$ [13], $\mathrm{SnO}_{2}$ [14] and $\mathrm{ZnS}-\mathrm{ZnO}$ heterostructures [15].

$\mathrm{ZnO}$, as an important semiconductor material, has a wide variety of applications in pigments [16], field effect transistors [17], field emitters [18], ultraviolet detectors [19], cosmetics [20] and energy storage [2123]. To date, various splendid morphologies of $\mathrm{ZnO}$ nanostructures have been reported by different synthesis approaches including thermal evaporation [24-26], hydrothermal reaction [27-29], electrochemical deposition [30-31]. Among them, the solution approach has been proved to be an efficient way with outstanding advantages, such as simplicity, commercial feasibility and potential for scaling up.

Key Laboratory of Semiconductor Nanocomposite Materials, Ministry of Education and College of Chemistry and Chemical Engineering, Harbin Normal University, Harbin 150025, P. R. China

*Corresponding author. E-mail: wuxiang05@gmail.com 
In the literature, there are some reports about $\mathrm{ZnO}$ micro/nanoflowers. Ogale et al. synthesized $\mathrm{ZnO}$ nanoflowers loaded with gold nanoparticles at $180^{\circ} \mathrm{C}$ and studied the power conversion efficiency of dyesensitized solar cells based on the $\mathrm{ZnO}$ nanoflowers with gold nanoparticles [32]. Tang's group reported 3D $\mathrm{ZnO}$ flowerlike nanostructure and the nanorods assembling flowers possess hexagonal shapes [33]. Prabakar and his coworkers synthesized $\mathrm{ZnO}$ nanoflowers through spin coating a film seed layer on FTO substrate [34]. Jiang et al. also reported $\mathrm{ZnO}$ nanoflowers through a hydrothermal method [35]. However, in the reports mentioned above, the nanorods composing the flowers are either smooth top or hexagonal shape: none of them investigated the effect of nanorod diameter on the luminescence property. In this study, we reported the fabrication of flowerlike $\mathrm{ZnO}$ micro/nanostructures through an assembly of the nanorods with the tip tops via a simple solution strategy without using any surfactant or template at mild temperature. The morphologies of the $\mathrm{ZnO}$ micro/nanostructures can be tunable by adjusting the growth parameters, such as solution basicity, reaction temperature and time. Cathodoluminescence (CL) properties of the as-prepared $\mathrm{ZnO}$ products were investigated by comparing the spectra recorded at different parts of the nanorods. Our strategy of assembly of nanorods into microflowers can be extended to some other compounds and even complex micro/nanostructures with ultrahigh surface areas towards the exploration of their unique functional properties.

$\mathrm{ZnO}$ microflowers were fabricated via a simple hydrothermal route. All reagents are analytical grade and were used without further purification. In a typical procedure, $0.352 \mathrm{~g}$ zinc acetate dehydrate $\left(\mathrm{Zn}(\mathrm{Ac})_{2} \cdot 2 \mathrm{H}_{2} \mathrm{O}\right)$ was first dissolved into $30 \mathrm{ml}$ de-ionized water and 1.12 $\mathrm{g} \mathrm{KOH}$ was dissolved into $5 \mathrm{ml}$ de-ionized water. The solution of $\mathrm{KOH}$ was then added dropwise into the above zinc acetate solution under continuous magnetic stirring for 10 minutes at room temperature. Afterward, the above mixture of solution was transferred into a stainless steel autoclave with a $50 \mathrm{ml}$ PTFE container and maintained at $150^{\circ} \mathrm{C}$ for $20 \mathrm{~h}$. After the reaction, the autoclave was naturally cooled to room temperature. The resulting products were collected, washed several times with de-ionized water and alcohol in sequence, and finally dried at $60^{\circ} \mathrm{C}$ for $12 \mathrm{~h}$.

The phase of the as-obtained products were examined using x-ray powder diffraction (XRD, Rigaku Dmax$\mathrm{rB}, \mathrm{CuK} \alpha$ radiation, $\lambda=0.1542 \mathrm{~nm}, 40 \mathrm{KV}, 100 \mathrm{~mA})$. The morphology and microstructure of the samples were characterized with scanning electron microscope (SEM, Hitachi-4800) and transmission electron microscope (TEM, JEOL-3010). The samples for TEM were prepared by suspending the synthesized $\mathrm{ZnO}$ product in absolute ethanol by ultrasonic treatment for 5 min- utes and then transferring onto a carbon-coated copper grid. The copper grid was air-dried under ambient conditions. Cathodoluminescence (CL) properties were investigated using a thermal field emission scanning electron microscope (Hitachi S4200) equipped with a CL system. The CL spectra and images were taken at room temperature at $3 \mathrm{kV}$ and $320 \mathrm{pA}$.

Figure 1 shows a typical XRD pattern of the asobtained product. All of the peaks match well with the bulk $\mathrm{ZnO}$, which can be indexed to the hexagonal wurtzite structure of $\mathrm{ZnO}$ (JCPDS card No. 05-0664). No peaks were observed from other impurities such as $\mathrm{Zn}(\mathrm{OH})_{2}$, which suggests that as-synthesized product is pure $\mathrm{ZnO}$.

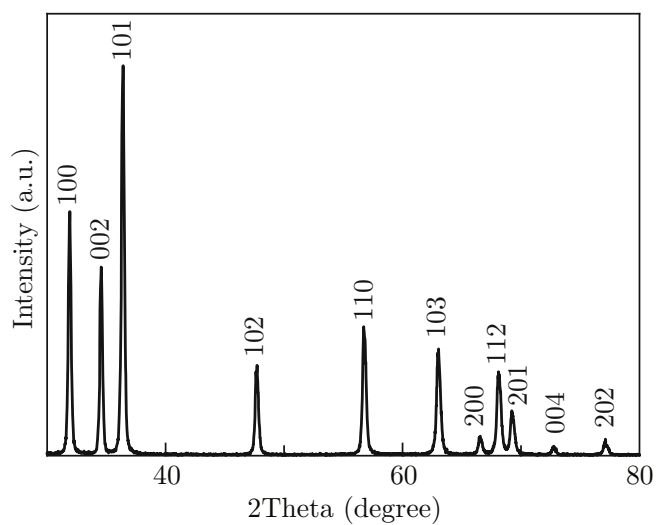

Fig. 1 XRD pattern of the as-synthesized $\mathrm{ZnO}$ microflowers.

Representative morphologies of the as-synthesized $\mathrm{ZnO}$ micro/nanostructures, as revealed by SEM, are shown in Fig. 2(a)-(b). As seen from the low magnification SEM images (Fig. 2(a)), uniform flowerlike nanostructures were obtained with high yield. These flowerlike structures have an average diameter of $2 \mu \mathrm{m}$ and are composed of nanorods radially branching out from the center (see in Fig. 2(b)). The average diameter of each nanorod is $200 \mathrm{~nm}$ and with a sharp tips. It is realized that this kind of tapered nanorod has a different luminescence property, which will be discussed later. Figure 2(c) shows a typical TEM image of a single microflower. The high resolution lattice TEM (HRTEM) image taken in the red square region (shown in Fig. 2(d)) gives a lattice fringe separation of $0.52 \mathrm{~nm}$, corresponding to the (0001) spacing. The corresponding fast Fourier transform (FFT) pattern (the inset in Fig. 2(d)) confirms a single crystal structure with the growth direction along the [0001] direction.

In order to investigate the formation process of the $\mathrm{ZnO}$ microflowers, a series of controlled experiments were performed through adjusting several growth parameters, such as reaction temperature, reaction time, dose of the alkali solution and organic solvent. First, SEM images of the products from time-dependent experiments are shown in Fig. 3. When the reaction time 

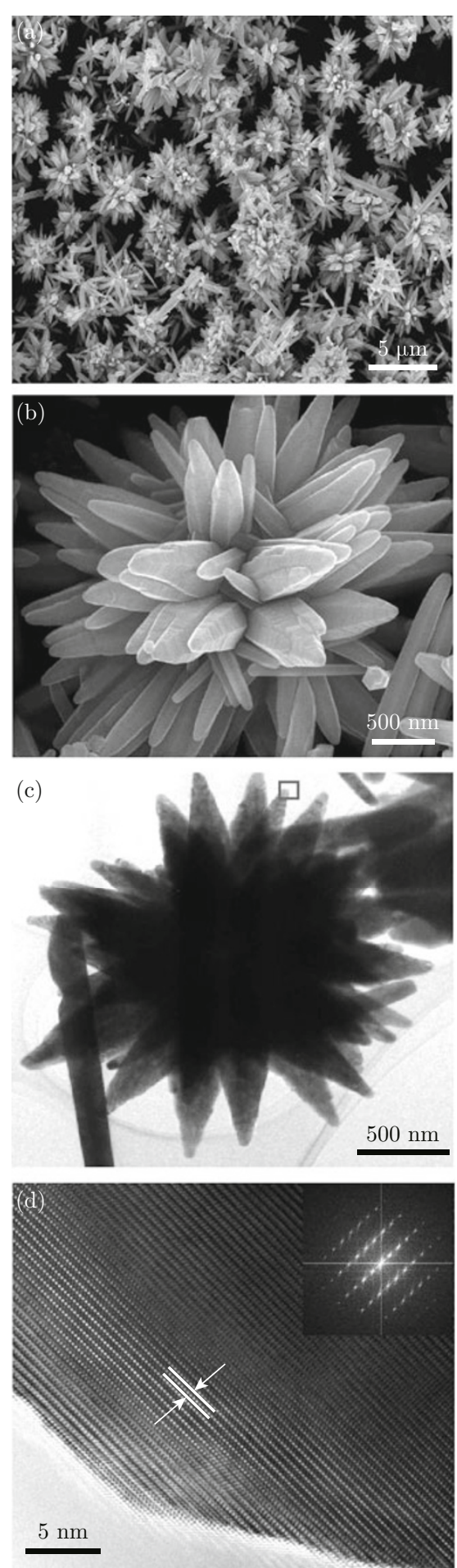

Fig. 2 SEM and TEM images of as-synthesized $\mathrm{ZnO}$ microflowers: (a) Low magnification SEM images; (b) High magnification SEM images of single microflower; (c) Low magnification TEM image of single microflower; (d) HRTEM image in Fig. 2(c). The inset is the corresponding SAED pattern.

is $5 \mathrm{~h}$, only a few microflowers appear while the majorities are incomplete flowers or disperse nanorods (indicated by the blue circle in Fig. 3(a)). With the reaction
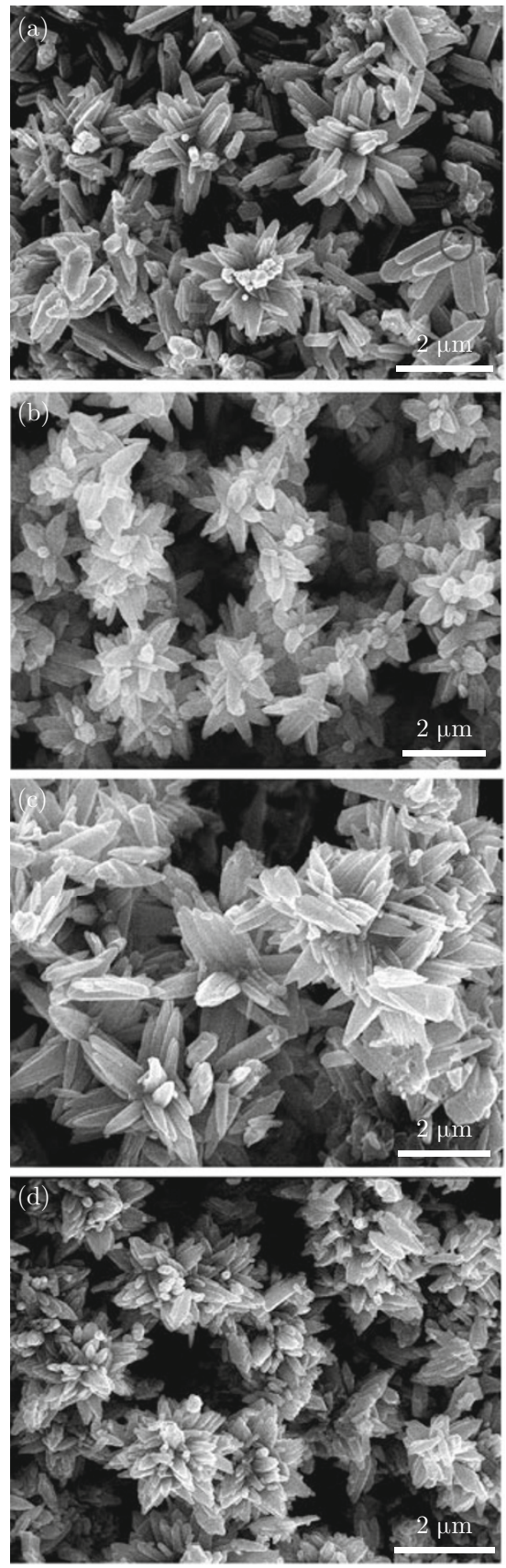

Fig. 3 SEM images of the products from reaction time dependent experiments: (a) $5 \mathrm{~h}$; (b) $20 \mathrm{~h}$; (c) $30 \mathrm{~h}$ and (d) 48 h.

time increased to $20 \mathrm{~h}$, the as-obtained product is composed of nearly pure microflowers with an average diameter of $2 \mu \mathrm{m}$, as shown in Fig. 3(b). With further elongation of the reaction time to $30 \mathrm{~h}$ (Fig. 3(c)) and even to 48 h (Fig. 3(d)), the flowerlike morphology still retains whereas the nanorods tend to bundle together forming a sheet-like structure.

Since the growth of micro/nanostructure undergoes a series of continuous reaction process for nucleation and growth, reaction temperature plays an important role in tailoring the final morphology. The above-shown 
microflowers were formed from a reaction at $150^{\circ} \mathrm{C}$ for $20 \mathrm{~h}$. When the temperature was reduced to $100^{\circ} \mathrm{C}$ with other conditions remain unchanged, the obtained microflowers were not uniform, and more than one microflowers attach each other, as revealed in Fig. 4(a). At the elevated temperature of $180^{\circ} \mathrm{C}$, some small particles and rods appeared lying randomly on the microflowers. Further increasing the temperature to $220^{\circ} \mathrm{C}$ resulted in disappearance of the microflowers and only some microcrystals or nanorods were observed. Hence, the optimum temperature is determined to be $150^{\circ} \mathrm{C}$.

Furthermore, the dosage of alkali is expected to have a decisive influence on morphology of the resultant
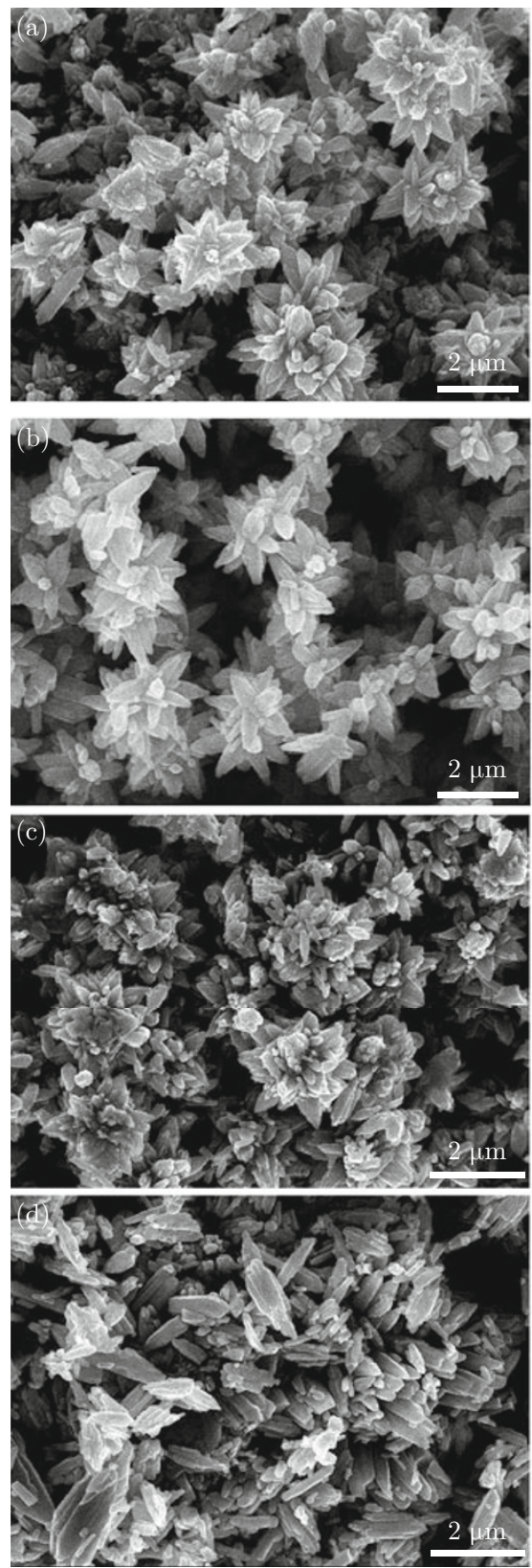

Fig. 4 SEM images of the products from reaction temperature dependent experiments: (a) $100^{\circ} \mathrm{C}$; (b) $150^{\circ} \mathrm{C}$; (c) $180^{\circ} \mathrm{Cand}(\mathrm{d}) 220^{\circ} \mathrm{C}$. products due to the participation of $\mathrm{OH}^{-}$ions in the nucleation and formation of the seeds. SEM images of the as-obtained products with different dosage of akali $(0.6 \mathrm{~g}$ and $1.0 \mathrm{~g})$ are shown in Fig. 5(a)-(b). One can see that a small amount of alkali $(0.6 \mathrm{~g})$ resulted in only some sheets and poor-defined particles. Finally, different zinc salts were also found to induce changes in the morphology of the as-obtained product. The SEM image in Fig. 5(c) shows that only separated nanorods can be seen, without the assembly into microflowers, when $\mathrm{Zn}(\mathrm{Ac})_{2}$ was replaced by $\mathrm{ZnSO}_{4}$ with other growth conditions kept the same as in Fig. 2. Under the condition that $\mathrm{Zn}\left(\mathrm{NO}_{3}\right)_{2}$ was used, microflowers appeared but the nanorods are connected each other into sheets, as indicated by the rectangle in Fig. 5(d). Finally, as a typical additive in hydrothermal growth of $\mathrm{ZnO}$ nanorods, effect of hexamethylenetetramine (HMT) on the morphology of the as-synthesized product was also studied. It is found that addition of HMT also prevents the formation of microflowers (see Fig. 5(e)-(f)). These results reveal that the resultant morphology of the as-obtained product is a result of a delicate interplay of various parameters; On the other hand, such dependence allows one to tune the desired structure of the final product for applications in which either a high aspect ratio or a high structural integrity is desired.

The formation process of crystals involves two stages: nucleation and growth. External parameters may pose dramatic effects on the size and morphology of the final crystal depending on the degree of participation during the nucleation and initial growth. The overall reaction for $\mathrm{ZnO}$ micro/nanostructures in an alkaline solution can be proposed as follows:

$$
\begin{aligned}
& \mathrm{Zn}^{2+}+2 \mathrm{OH}^{-} \longrightarrow \mathrm{Zn}(\mathrm{OH})_{2} \\
& \mathrm{Zn}(\mathrm{OH})_{2}+2 \mathrm{OH}^{-} \longrightarrow \mathrm{Zn}(\mathrm{OH})_{4}^{2-} \\
& \mathrm{Zn}(\mathrm{OH})_{4}^{2-} \longrightarrow \mathrm{ZnO}+2 \mathrm{H}_{2} \mathrm{O}+2 \mathrm{OH}^{-}
\end{aligned}
$$

In literature, Kim et al. synthesized $\mathrm{ZnO}$ nanoflower arrays through using a pre-patterned PMMA mask on the $\mathrm{ZnO}$ seed layer deposited on fluorine-doped tin oxide (FTO) glass [36]. Zhang et al. reported flowerlike nanostructures of $\mathrm{ZnO}$ by treating $\mathrm{Zn}(\mathrm{OH})_{4}^{2-}$ precursor in water at $180^{\circ} \mathrm{C}$, and investigated the shape evolution induced by several growth parameters [37]. Ni et al. proposed the formation of $\mathrm{ZnO}$ flower-like structures is sensitive to the amount of ammonia used in the system [8]. This is also the case in our experiment. When the quantity of alkali is small, only some sheets and particles appear, as shown in Fig. 5(a)-(b). Due to the coordination effect of $\mathrm{OH}^{-}$ions to $\mathrm{Zn}^{2+}$ ions, it is possible that $\mathrm{OH}^{-}$ions are adsorbed at the circumference of $\mathrm{Zn}$ ions of the $\mathrm{ZnO}$ nuclei. Due to the spatial hindrance, $\mathrm{ZnO}$ grew only along certain directions, which leads the formation of flowerlike structure [8]. Gao et al believed that the introduction of HMT has an important 

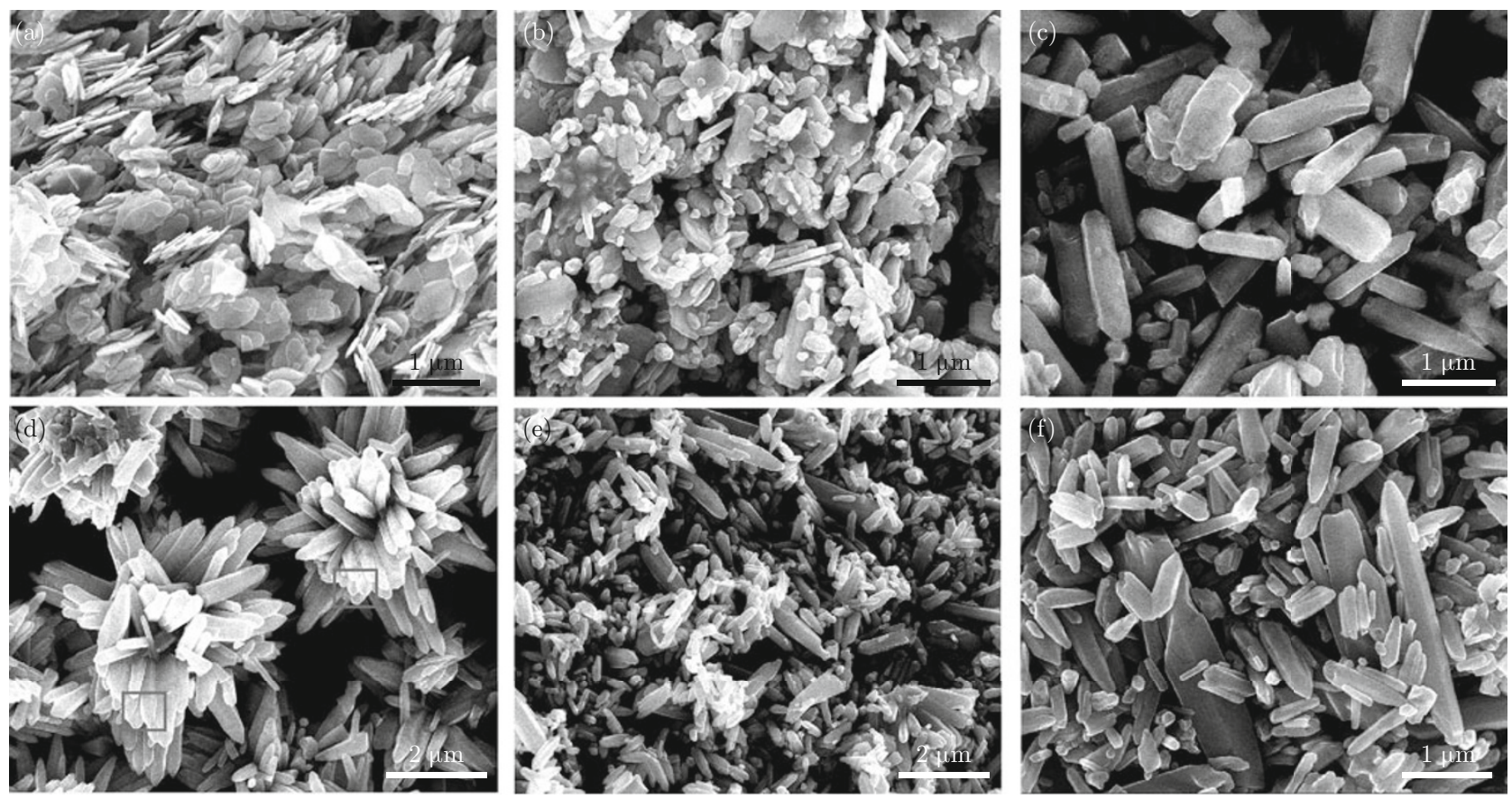

Fig. 5 SEM images of the as-obtained product obtained with different dosage of alkali (0.6 g and $1.0 \mathrm{~g})$ (a-b); with different types of zinc sources $\left[\mathrm{ZnSO}_{4}\right.$ and $\left.\mathrm{Zn}\left(\mathrm{NO}_{3}\right)_{2}\right]$ (c-d) and with addition of HMT (e-f).

influence on the formation of $\mathrm{ZnO}$ flowerlike structures [38]. However, this is not the case in our experiments.

Figure 6 shows a typical CL spectrum obtained at room temperature from the $\mathrm{ZnO}$ microflowers. The corresponding SEM image is shown in Fig. 6(a). The CL spectra recorded from five spots corresponding to different diameters on a nanorod are recorded. Clearly all spectra have an ultraviolet emission peak at $\sim 388$ $\mathrm{nm}$ and a broad green emission peak ranging from 521 to $539 \mathrm{~nm}$. It is noted that the emission intensity become lower with decreasing diameter. Location of visible emission peaks from spot 1 to spot 5 are $521 \mathrm{~nm}$, $539 \mathrm{~nm}, 537 \mathrm{~nm}, 532 \mathrm{~nm}$ and $528 \mathrm{~nm}$, respectively. The UV emission peak of the microflowers in this work is $388 \mathrm{~nm}$, which is in good agreement with the typically reported free exciton peak position and could be attributed to UV near-band edge emission [39]. The impurities and structural defects, such as oxygen vacancies and so forth, are responsible for the deep level or trap-state emission in the visible range [40]. For the visible green emission peaks in CL spectrum, it is generally accepted that the green emission originates from the radiative recombination of a photogenerated hole with an electron occupying the oxygen vacancy [41-42]. $\mathrm{Li}$ et al. attributed the green emission to point defects, which can easily form recombination center [43]. In our experiment, when the as-synthesized $\mathrm{ZnO}$ nanostructures were dried at $60^{\circ} \mathrm{C}$ for $12 \mathrm{~h}$ in air ambient, the surface of the microflowers would get rougher, revealing that there are abundant surface defects in the product. Taking large surface volume ratio in microflower
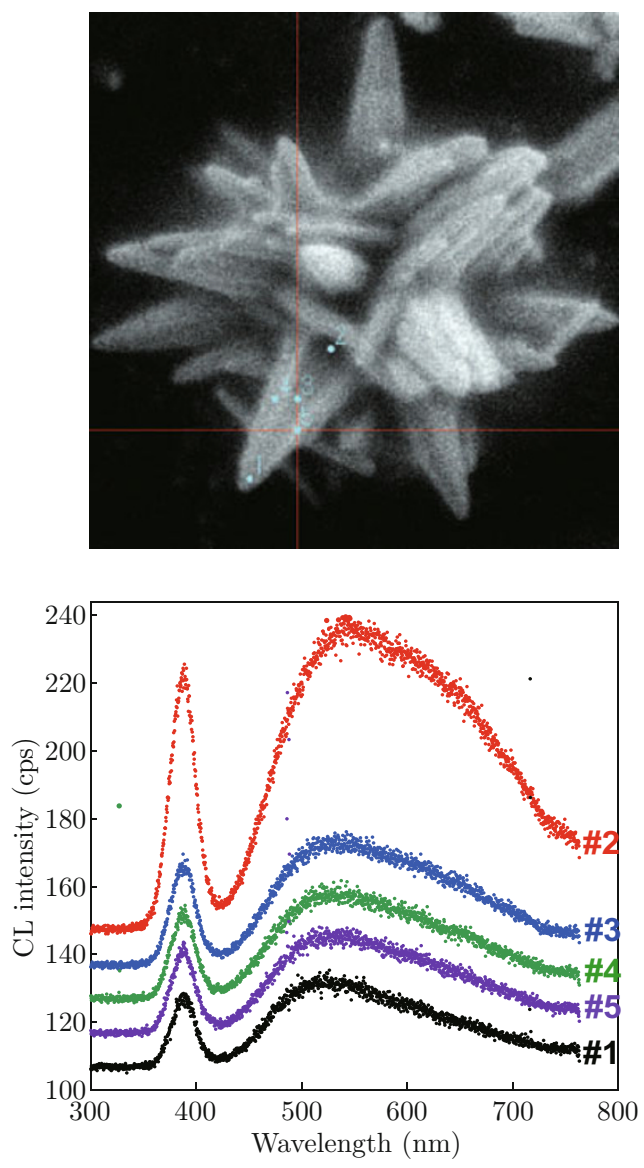

Fig. 6 SEM image (a) and CL image (b) of the $\mathrm{ZnO}$ microflowers recorded at $3 \mathrm{kV}$ and $320 \mathrm{pA}$ and at room temperature. 
structures into account, the broadening and enhancement of the green emission peak can be ascribed to abundant surface defects. Abundant defects at the surface of $\mathrm{ZnO}$ microflowers can provide new states as visible luminescence centers and broaden the visible emission band.

In summary, we reported an easy and efficient hydrothermal method to synthesize $\mathrm{ZnO}$ microflowers through the self-assembly of nanorods at a mild temperature $\left(150^{\circ} \mathrm{C}\right)$. A series of control experiments by adjusting several growth parameters were conducted which allows a systematic investigation of the growth process. Optical properties of the as-synthesized $\mathrm{ZnO}$ microflowers have been studied, which show both sharp ultraviolet emission peaks and broad green peaks. The emission intensity lowers with decreasing diameter. The $\mathrm{ZnO}$ microflowers obtained herein may have potential applications in photocatalyst or photoelectrochemical cells.

\section{Acknowledgement}

This work was supported by the Foundation for Key Project of Ministry of Education, China (No. 211046), Open Fund of State Key Laboratory for Modification of Chemical Fibers and Polymer Materials, Dong Hua University (No. K1012), Open Fund State Key Laboratory of Inorganic Synthesis and Preparative Chemistry, College of Chemistry, Jilin University, Changchun 130012, P. R. China (No. 2012-22) and Program for New Century Excellent Talents in Heilongjiang Provincial University.

\section{References}

[1] H. B. Zeng, W. P. Cai, P. S. Liu, X. X. Xu, H. Zhou, C. Klingshirn and H. Kalt, ACS Nano 2, 1661 (2008). http://dx.doi.org/10.1021/nn800353q

[2] Y. T. Han, X. Wu, G. Z. Shen, B. Dierre, L. H. Gong, F. Y. Qu, Y. Bando, T. Sekiguchi, F. Fabbri and D. Golberg, J. Phys. Chem. C 114, 8235 (2010). http:// dx.doi.org/10.1021/jp100942m

[3] H. B. Zeng, G. T. Duan, Y. Li, S. K. Yang, X. X. $\mathrm{Xu}$ and W. P. Cai, Adv. Funct. Mater. 20, 561 (2010). http://dx.doi.org/10.1002/adfm. 200901884

[4] Z. X. Zhang, L. F. Sun, Y. C. Zhao, Z. Liu, D. F. Liu, L. Cao, B. S. Zou, W. Y. Zhou, C. Z. Gu and S. S. Xie, Nano Lett. 8, 652 (2008). http://dx.doi.org/ 10.1021/n10730880

[5] W. L. Cheng, M. J. Campolongo, J. J. Cha, S. J. Tan, C. C. Umbach, D. A. Muller and D. Luo, Nature Mater. 8, 519 (2009). http://dx.doi.org/10.1038/ nmat 2440

[6] C. W. Cheng, B. Liu, H. Y. Yang, W. W. Zhou, L. Sun, R. Chen, S. F. Yu, J. X. Zhang, H. Gong, H. D. Sun and H. J. Fan, ACSNano 3, 3069 (2010). http: // dx.doi.org/10.1021/nn900848x
[7] K. A. Dick, K. Deppert, M. W. Larsson, T. Martensson, W. Seifert, L. R. Wallenberg and L. Samuelson, Nature Mater. 3, 380 (2004). http://dx.doi.org/10. 1038/nmat1133

[8] Y. H. Ni, S. Yang, J. M. Hong, L. Zhang, W. L. Wu and Z. S. Yang, J. Phys. Chem. C 112, 8200 (2008). http://dx.doi.org/10.1021/jp711539u

[9] L. L. Zhao, X. H. Ji, X. J. Sun, J. Li, W. S. Yang and X. G. Peng, J. Phys. Chem. C 113, 16645 (2009). http://dx.doi.org/10.1021/jp9058406

[10] X. J. Dai,Y. S. Luo, S. Y. Fu, W. Q. Chen and Y. Lu, Solid State Sci. 12, 637 (2010). http://dx.doi.org/ 10.1016/j.solidstatesciences. 2010.01.024

[11] G. Z. Shen, D. Chen, K. B. Tang, F. Q. Li and Y. T. Qian, Chem. Phys. Lett. 370, 334 (2003). http://dx. doi.org/10.1016/S0009-2614(03)00131-3

[12] X.Wu, F. Y. Qu, G. Z. Shen and W. Cai, J. Alloys. Compd. 482, L32 (2009). http://dx.doi.org/ 10.1016/j.jallcom. 2009.04.070

[13] G. Z. Shen, P. C. Chen, Y. bando, D. Golberg and C. W. Zhou, Chem. Mater. 20, 6779 (2008). http://dx. doi.org/10.1021/cm802042k

[14] X. Wu, J. H. Sui, W. Cai and F. Y. Qu, Mater. Chem. Phys. 112, 325 (2008). http://dx.doi.org/10.1016/ j.matchemphys. 2008.05.069

[15] X. Wu, P. Jiang, Y. Ding, W. Cai, S. S. Xie and Z. L. Wang, Adv. Mater. 19, 2319 (2007). http://dx.doi. org/10.1002/adma. 200602698

[16] P. Sulcova and M. Trojan, Dyes. Pigments. 40, 83 (1999). http://dx.doi.org/10.1016/ S0143-7208(98) 00036-9

[17] H. B. Chen, X. Wu, L. H. Gong, C. Ye, F. Y. Qu and G. Z. Shen, Nanoscale Res. Lett. 5, 570 (2010). http://dx.doi.org/10.1007/s11671-009-9506-4

[18] G. Z. Shen, Y. Bando, B. D. Liu, D. Golberg and C. J. Lee, Adv. Funct. Mater. 16, 410 (2006). http://dx. doi.org/10.1002/adfm. 200500571

[19] Y. H. Li, J. Gong and Y. L. Deng, Sens. Actuat. A 158, 176 (2010). http://dx.doi.org/10.1016/j.sna. 2009.12.030

[20] A. O. Gamer, E. Leibold and B. V. Ravenzwaay, Toxicol. in Vitro 20, 301(2006). http://dx.doi.org/10. 1016/j.tiv. 2005.08.008

[21] M. P. Lu, J. H. Song, M.Y. Lu, M. T. Chen, Y. F. Gao, L. J. Chen and Z. L. Wang, Nano Lett. 9, 1223 (2009). http://dx.doi.org/10.1021/nl900115y

[22] Z. L. Wang and J. H. Song, Science 312, 242 (2006). http://dx.doi.org/10.1126/science. 1124005

[23] X. D. Wang, J. H. Song, J. Liu and Z. L.Wang, Science 31, 102 (2007). http://dx.doi.org/10.1126/ science. 1139366

[24] X. Wu, P. Jiang, W. Cai, X. D. Bai, P. Gao and S. S. Xie. Adv. Engn. Mater. 10, 476 (2008). http://dx. doi.org/10.1002/adem. 200700320

[25] X. Wu, W. Cai, F. Y. Qu, Chin. Phys. B 18,1669 (2009). http://dx.doi.org/10.1088/1674-1056/18/ $4 / 065$

[26] X.Wu, W. Cai, F.Y. Qu, Acta Phys. Sin. 58, 8044 (2009). 
[27] L. J. Yu, F. Y. Qu and X. Wu, J. Alloys Compd. 504, L1 (2010). http://dx.doi.org/10.1016/j.jallcom. 2010.05.055

[28] L. J. Yu, F. Y. Qu and X. Wu, Appl. Sur. Sci.257, 7432 (2011). http://dx.doi.org/10.1016/j.apsusc. 2011.02 .130

[29] L. H. Gong, X. Wu, C. Ye, F. Y. Qu and M. Z. An, J. Alloys Compd. 501, 375 (2010). http://dx.doi.org/ 10.1016/j.jallcom. 2010.04.110

[30] J. Elias, C. C. Levy, M. Bechelany, J. Michler, G. Y. Wang, Z. Wang and L. Philippe, Adv. Mater., 22, 1607 (2010). http://dx.doi.org/10.1002/adma. 200903098

[31] L. Li, S. S Pan, X. C. Dou, Y. G. Zhu, X. H. Huang, Y. W. Yang, G. H. Li and L. D. Zhang, J. Phys. Chem. C 118, 7288 (2007). http://dx.doi.org/10. 1021/jp0711242

[32] V. Dhas, S. Muduli, W. Lee, S. H. Han and S. Ogale, Appl. Phys. Lett. 93, 243108 (2008). http://dx.doi. org/10.1063/1.3049131

[33] Z. Fang, K. B. Tang, G. Z. Shen, D. Chen, R Kong and S. J. Lei, Mater. Lett. 60,2530 (2006). http://dx.doi. org/10.1016/j.matlet. 2006.01.034

[34] K. Prabakar, M. K. Son, W.Y. Kim and H. Kim, Mater. Chem. Phys. 125,12 (2011). http://dx.doi. org/10.1016/j.matchemphys. 2010.09.028

[35] C. Y. Jiang, X. W. Sun, G. Q. Lo, D. L. Kwong and J. X. Wang, Appl. Phys. Lett. 90, 263501 (2007). http:// dx.doi.org/10.1063/1.2751588
[36] Y. J. Kim, J. K.Yoo, B. H. Kwon,Y. J. Hong, C. H. Lee and G. C. Yi, Nanotechnology 19, 315202 (2008). http://dx.doi.org/10.1088/0957-4484/19/ $31 / 315202$

[37] J. Zhang, L. D. Sun, J. L. Yin, H. L. Su, C. S. Liao and C. H. Yan, Chem. Mater. 14, 4172 (2002). http://dx. doi.org/10.1021/cm020077h

[38] Y. J. Gao, W. C. Zhang, X. L. Wu, G. S. Huang, L. L. Xu, J. C. Shen, G. G. Siu and P. K. Chu, Appl. Surf. Sci., 255, 1982 (2008). http://dx.doi.org/10.1016/ j.apsusc. 2008.06.137

[39] M. H. Huang, Y. Wu, H. Feick, N. Tran, E. Weber and P. Yang, Adv. Mater. 13, 113 (2001). http://dx.doi.org/10.1002/ 1521-4095 (200101) 13: 2\$\delimiter"426830A\$113: : AID-ADMA113\$ \delimiter"526930B\$3 . 0.CO;2-H

[40] G. Z. Shen, Y. Bando, B. D. Liu, D. Golberg and C. J. Lee, Adv. Fuct. Mater. 16, 410 (2006). http://dx. doi.org/10.1002/adfm. 200500571

[41] A. Umar and Y. B. Hahn, Appl. Phys. Lett. 88, 173120 (2006). http://dx.doi.org/10.1063/1.2200472

[42] K. Vanheusden, W. L. Warren, C. H. Seager, D. R. Tallant, J. A. Voigt and B. E. Gnade, J. Appl. Phys. 79, 7983 (1996). http://dx.doi.org/10.1063/1.362349

[43] B. X. Li, Z. X. Fu and Y. B. Jia, Appl. Phys. Lett. 79, 943 (2001). http://dx.doi.org/10.1063/1.1394173 